\title{
Critical Mass Pyrolysis Rates for Extinction of Fires over Solid Materials
}

\author{
MICHAEL A. DELICHATSIOS and MARY M. DELICHATSIOS \\ Factory Mutual Research Corporation \\ Norwood, MA 02062 USA
}

\begin{abstract}
New flame extinction conditions for the critical mass pyrolysis rate are developed when extinction occurs by interaction of flames with the pyrolyzing surface of a condensed material. The extinction conditions provide the critical mass pyrolysis rate and the corresponding convective heat flux to the surface. A novel formulation shows that the sum of fuel mass fraction near the surface and the ambient oxygen mass fraction corrected for stoichiometry and incompleteness of combustion is constant. The extinction conditions are derived from simple analysis of combustion and heat transfer, and they are shown to be applicable for various experimental conditions such as fuel dilution by inert gas, oxygen dilution by inert gas, effects of external heat flux, material preheating, transient (charring) pyrolysis, including geometric effects which influence the critical mass pyrolysis rate through an effective heat transfer coefficient. Additional validation of the proposed extinction conditions is provided by numerical simulation reported in the literature in the regime of low straining rates for a stagnation flow on a cylinder. The present approach can be used to obtain the critical extinction conditions from measurements in a standard flammability apparatus.
\end{abstract}

KEYWORDS: Fire Extinguishment, Solid Material Fires, Critical Extinction Conditions

\section{INTRODUCTION}

We present a definitive way for determining extinction conditions of a fire over a pyrolyzing surface when the mass pyrolysis rate decreases because of the action of an extinguishment agent (such as water on the surface or a gaseous agent) or because of transient pyrolysis resulting from char formation. Analytical solutions are based on asymptotic methods of combustion for a single Arrhenius reaction founded on methodologies developed by Russian scientists[1], Friedlander[2], Fendell[3], and Linan[4]. In these models, the gaseous reactions are modified in their interaction with the surface pyrolysis through an energy balance (Law[5], Sibulkin[6]). These analytical models and results have the following drawbacks: 1) They do not separate clearly the gaseous combustion dynamics from the energy balance near the surface; 2) As a consequence, it is not transparent how to use these (asymptotic) analytical results to characterize extinction of fires over a solid material, considering the fact that: a) the analytical solutions use assumed kinetics; and b) the 
chemical kinetics of a solid material are not known. On the practical side, several empirical conditions have been proposed for critical pyrolysis extinction conditions (see Beyler[7] for a systematic discussion). The empirical conditions near extinction can be classified as: 1) The flame temperature decreases below a critical value owing to cooling by the surface[7,8]; 2) The mass pyrolysis is less than a critical mass pyrolysis rate[7,8]; and 3) The flame heat flux to the surface is proportional to mass pyrolysis rate[8].

Each of these empirical conditions contain only part of the true extinction conditions and they are inconsistent and deficient in certain applications[7]; it can be shown that none of these conditions can explain all experimental results. The new extinction conditions presented in this work are derived in the following two sections by separating the dynamics of gaseous reactions from the energy balance in the solid material using a simple physical interpretation; validation by comparison with experiments is established next, followed by discussion, comparison with analytical solutions and conclusions.

\section{ENERGY BALANCE AT SOLID FUEL SURFACE}

For steady state flames over a solid fuel, an energy balance equation at the surface relates mass pyrolysis rates to imposed heat fluxes and heat drains such as by water application:

$\dot{\mathrm{m}}_{\mathrm{p}}^{\prime \prime} \Delta \mathrm{H}_{\mathrm{v}}+\dot{\mathrm{m}}_{\mathrm{w}}^{\prime \prime} \mathrm{L}_{\mathrm{w}}=\dot{\mathrm{q}}_{\mathrm{c}}^{\prime \prime}-\dot{\mathrm{q}}_{\mathrm{rr}}^{\prime \prime}+\dot{\mathrm{q}}_{\mathrm{rf}}^{\prime \prime}+\dot{\mathrm{q}}_{\mathrm{e}}^{\prime \prime}$

Here, $\dot{\mathrm{m}}_{\mathrm{p}}^{\prime \prime}$ is the mass pyrolysis rate, $\Delta \mathrm{H}_{\mathrm{v}}$ is the effective heat of pyrolysis, $\dot{\mathrm{m}}_{\mathrm{w}}^{\prime \prime}$ is the water application rate, $L_{w}$ is the effective heat for water vaporization; in addition, $\dot{\mathrm{q}}_{\mathrm{c}}^{\prime \prime}, \dot{\mathrm{q}}_{\mathrm{r}}^{\prime \prime}, \dot{\mathrm{q}}_{\mathrm{rf}}^{\prime \prime}, \dot{\mathrm{q}}_{\mathrm{e}}^{\prime \prime}$ are convective, reradiative, flame radiation, and external heat fluxes, respectively. Near extinction, as the mass pyrolysis rate decreases (for example, due to water application or oxidant stream inerting), steady (gaseous) flames can no longer exist. This causes the pyrolysis rate to further decay and eventually decrease to zero if no external flux is imposed. The critical pyrolysis rate at extinction is defined as the minimum pyrolysis rate for which steady burning exists. We can simplify the extinction problem for understanding the physics by observing that a connection is manifested between the energy balance, Eq. 1, and gaseous combustion dynamics through the convective term $\dot{\mathrm{q}}_{\mathrm{c}}^{\prime \prime}$. We proceed by writing Eq. 1 as:

$\dot{m}_{p}{ }^{\prime \prime}\left(\Delta H_{v}+\frac{\dot{m}_{w}{ }^{\prime} L_{w}}{\dot{m}_{p}{ }^{\prime \prime}}+\frac{\dot{q}_{r}{ }^{\prime \prime}}{\dot{m}_{p}{ }^{\prime \prime}}-\frac{\dot{q}_{f}{ }^{\prime \prime}}{\dot{m}_{p}{ }^{\prime \prime}}-\frac{\dot{q}_{e}{ }^{\prime \prime}}{\dot{m}_{p}{ }^{\prime \prime}}\right)=\dot{q}_{c}{ }^{\prime \prime}$

or equivalently,

$\dot{\mathrm{m}}_{\mathrm{p}}^{\prime \prime} \Delta \tilde{\mathrm{H}}_{\mathrm{v}}=\dot{\mathrm{q}}_{\mathrm{c}}^{\prime \prime}$

where $\Delta \tilde{\mathrm{H}}_{\mathrm{v}}$ is equal to the term inside the parenthesis of Eq. 2a. For steady state conditions, Eq. 2a may be considered equivalent to Eq. $2 b$, where $\Delta \widetilde{\mathrm{H}}_{\mathrm{v}}$ is considered to have a fixed value. We can now decouple the gas combustion dynamics from the surface energy balance (Eqs. 2a and 2b) 
by considering the following burning problem: given a surface fuel pyrolysis rate $\dot{\mathrm{m}}_{\mathrm{p}}^{\prime \prime}$ at a fixed surface temperature $T_{w}$, how does the convective heat flux, $\dot{\mathrm{q}}_{\mathrm{c}}$, from an established diffusion flame near the surface vary as $\dot{\mathrm{m}}_{\mathrm{p}}^{\prime \prime}$ decreases until flame extinction occurs? Simulation of this process is done by using a porous gas burner $[9,13]$ so that the mass supply rate is an independent parameter. The flow field near the surface can be generated by buoyancy, or by a forced flow, or be controlled by diffusional transport only. The present discussion and approach is valid even though the radiant flame heat flux ( $\mathrm{q}_{\mathrm{rf}}$ " in Eq. 2a) varies with mass flux, because radiative heat feedback increases monotonically with mass flux and reaches a maximum (constant) value for a given system near or just after the convective heat flux becomes maximum[9].

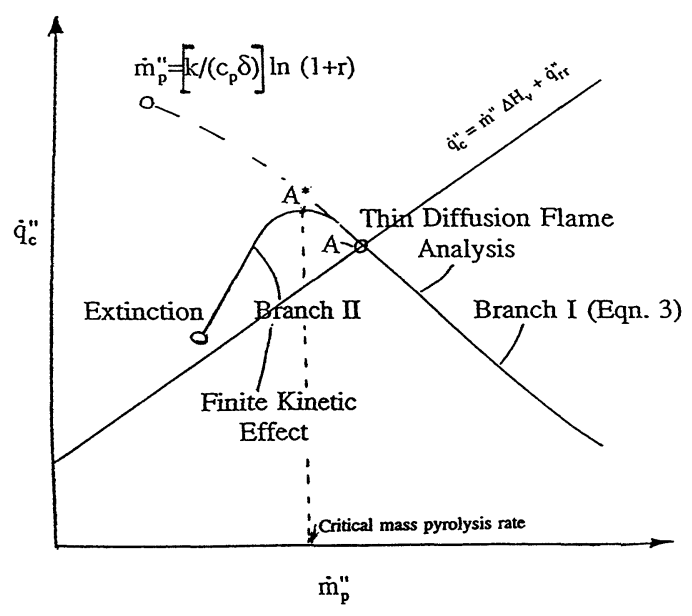

FIGURE 1. Expected convective heat flux variation with total mass pyrolysis rate and definition of steady pyrolysis state (point $\mathrm{A}$ ) and critical conditions for extinction (point $\mathrm{A}^{*}$ ).
Figure 1 illustrates the present concept. In this figure the convective heat flux is plotted as function of mass pyrolysis rate for a gaseous porous pool burner. As mass pyrolysis rate decreases, the convective heat flux increases because surface blowing is reduced until a maximum value of the convective heat flux is reached (Branch I in Fig. 1). Further decrease in pyrolysis rate is followed by decrease in the convective heat flux because the flame approaches the surface and partial flame quenching occurs leading eventually to complete extinction of flames (Branch II in Figure 1). More details shown in Figure 1 are also discussed and explained in the next section.

The mass flux corresponding to the maximum convective heat flux can be identified as the critical mass flux for extinction of a condensed material fire, as can be seen by examining the conditions for stable steady state

burning of a condensed material. These conditions are specified by the intersection of the surface energy balance equation (i.e., Eq. 1, wherein only convective flux and reradiation losses are considered) and the convective heat flux curve (see Fig. 1, point A). Near extinction, the surface energy balance line (Eq. 1) moves higher (e.g., because of increased water application rate), and the steady state burning condition (point A) moves along the stable branch I of the gaseous convective curve until it reaches the maximum convective heat flux at the corresponding critical mass pyrolysis rate. Strictly speaking, critical conditions exist when the surface energy loss curve is tangent to the convective heat flux curve (see Fig. 1); this point nearly coincides with the maximum value of the convective heat flux (at $\mathrm{A}^{*}$ in Fig. 1) because the slope of the surface energy loss curve (i.e., Eq. 1) is much smaller than the slope of the line to the left of $A^{*}$ in Fig.1 $[7,8,9]$. 


\section{FLAME CONVECTIVE HEAT FLUXES}

For simplicity, but with little loss of generality, we employ the flow field associated with a stagnant film having thickness $\delta$. In this situation, fuel is supplied on one side $(\mathrm{x}=0)$ at a fixed rate $\dot{\mathrm{m}}_{\mathrm{p}}$, while at the other side $(\mathrm{x}=\delta)$ ambient oxygen concentrations prevail. A characteristic straining rate in this flow, which can affect the chemistry (Damkohler effects), is $\mathrm{D} / \delta^{2}$, where $\mathrm{D}$ is the diffusivity which is assumed constant. For Branch I, we have the following relations for the mass pyrolysis rate, $\dot{\mathrm{m}}_{\mathrm{p}}^{\prime \prime}$, convective mass transfer number, $\mathrm{B}$, the convective heat flux $\dot{\mathrm{q}}_{\mathrm{c}}^{\prime \prime}$, and flame sheet enthalpy, $\mathrm{h}_{f}$ :

$$
\dot{\mathrm{m}}_{\mathrm{p}} "=\frac{k}{\mathrm{c}_{\mathrm{p}} \delta} \ln (1+\mathrm{B})
$$

where the mass transfer number is defined as:

$$
\mathrm{B}=\frac{\mathrm{Q}_{\mathrm{o}} \mathrm{Y}_{\mathrm{o}}-\left(\mathrm{h}_{\mathrm{w}}-\mathrm{h}_{\infty}\right)}{\Delta \widetilde{\mathrm{H}}_{\mathrm{v}}}=\frac{\mathrm{Q}_{\mathrm{o}} \mathrm{Y}_{\mathrm{o} \infty}-\left(\mathrm{h}_{\mathrm{w}}-\mathrm{h}_{\infty}\right)}{\dot{\mathrm{q}}_{\mathrm{c}}{ }^{\prime}} \dot{\mathrm{m}}_{\mathrm{p}} "
$$

Eqs. 3 and 4 determine the gas combustion dynamics in Branch I (Fig. 1). Here $\mathrm{k}$ is the thermal conductivity; $c_{p}$ is the specific heat of gas; $Q_{o}$ is the heat released per unit mass of oxygen; $Y_{o} \infty$ is the ambient oxygen mass fraction; $h_{w}, h \infty$ are the gas enthalpy at the wall and ambient temperatures, respectively. At large blowing rates the convective heat flux drops exponentially to zero $\left(\mathrm{q}_{\mathrm{c}}^{\prime \prime} \sim \mathrm{m}_{\mathrm{p}}^{\prime \prime} / \exp \left(\mathrm{m}_{\mathrm{p}}^{\prime \prime}\right)\right.$ as obtained from Eq. (3)) and the flame sheet moves away from the pyrolyzing surface. At low blowing rates, as the flame sheet approaches the pyrolyzing surface, the convective heat flux increases and reaches a theoretical maximum value, see Eq. $7 \mathrm{~b}$ derived later. To estimate the theoretical maximum value of $\dot{\mathrm{q}}_{\mathrm{c}}^{\prime \prime}$, we note that the flame temperature (enthalpy) is given by:

$$
h_{f}=h_{w}+\frac{Q_{o} Y_{o \infty}-\left(h_{w}-h_{\infty}\right)}{1+r}-\frac{r}{1+r} \frac{\dot{q}_{c}{ }^{\prime \prime}}{\dot{m}_{p}{ }^{\prime \prime}}
$$

where $\mathrm{r}$ is the fuel to air stoichiometric mass ratio:

$$
r=\frac{Y_{o \infty} V_{F} M_{F}}{Y_{F T} V_{o} M_{o}}
$$

The second term on RHS of Eq. 5 represents the adiabatic stoichiometric flame enthalpy and the last term in the RHS of Eq. 5 represents heat losses to the wall. In Eq. $6, v_{\mathrm{F}}, v_{\mathrm{o}}$, are stoichiometric coefficients for fuel and oxygen, $\mathrm{M}_{\mathrm{F}}, \mathrm{M}_{\mathrm{o}}$ are the molecular weights for fuel and oxygen, and $\mathrm{Y}_{\mathrm{FT}}$ is the fuel concentration in the supply stream. For infinitely fast kinetics, the flame sheet will lie on the pyrolyzing surface and the flame temperature will be equal to the wall temperature $\left(T_{f}=T_{w}\right.$ or $\mathrm{h}_{\mathrm{f}}=\mathrm{h}_{\mathrm{w}}$ ) so that Eq. 5 gives:

$$
\frac{\dot{q}_{c}{ }^{\prime \prime}}{\dot{m}_{p}{ }^{\prime \prime}}=\frac{Q_{o} Y_{o \infty}-\left(h_{w}-h_{\infty}\right)}{r}
$$


where the mass pyrolysis rate is obtained from Eqs. 3 and 4 using $B=r$ from Eqs. 4 and $7 \mathrm{a}$ :

$\left(\dot{\mathrm{m}}_{\mathrm{p}}{ }^{\prime}\right)_{\max , \text { th }}=\frac{\mathrm{k}}{\mathrm{c}_{\mathrm{p}} \delta} \ln (1+\mathrm{r})$

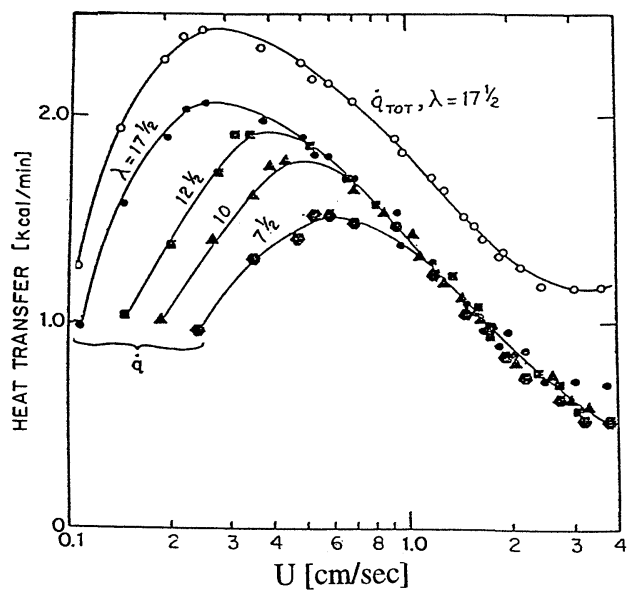

FIGURE 2a. Heat transfer data to the porous burner: Ethane-nitrogen system (porous burner diameter 4 in., lip height $1 / 4$ in.). Solid symbols represent convective heat fluxes, open symbols total heat fluxes; $\lambda$ is the air to fuel mole stoichiometric ratio, $U$ is the average fuel gas velocity at the burner (from Ref.9).

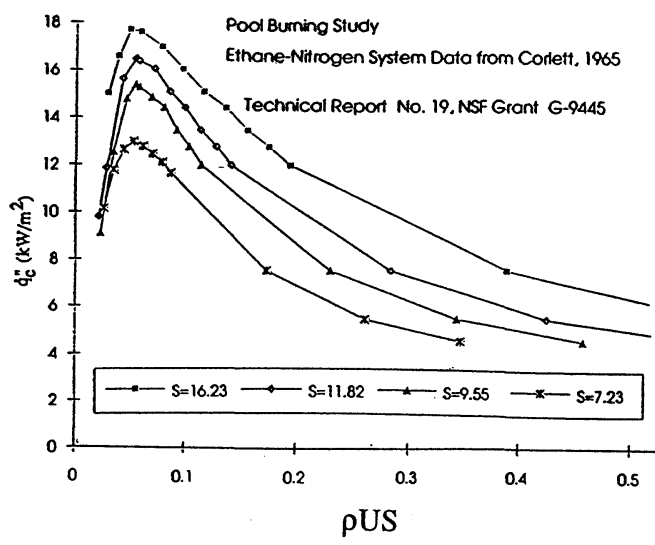

FIGURE: 2b. Convective heat flux to the porous burner versus the mass flux multiplied by the air to the fuel mass stoichiometric ratio (data are taken from Figure $2 a$ ). The abscissa is proportional to the ethane mass flux rate.

Eq. 7a gives the maximum theoretical convective heat flux that can be applied to the surface (see broken line in Fig. 1); this situation occurs for infinitely fast kinetics in the gaseous phase. However, this situation cannot occur in practice because the surface temperature is much less than the flame temperature. Instead, the convective heat transfer will decrease at small values of pyrolysis rate following the Branch II as is shown in Fig. 1, because of flame quenching. Deviation from Branch I will occur as soon as chemical kinetics times become comparable to flow times; in this case, pyrolysis rates decrease and flames approach the pyrolyzing surface. To proceed further with our physical picture, we make use of key experimental results. We reproduce in Figure 2a results obtained by Corlett[9] for heat transfer on horizontal porous burners supplying various gaseous fuels.

Effects of fuel dilution by nitrogen are shown in Figure 2a, where solid symbols represent convective heat fluxes and open symbols represent total heat fluxes. We can observe that for high mass flux pyrolysis rates, convective heat fluxes are independent of dilution; this regime corresponds to Branch I of Figure 1. There is another conclusion that can be drawn from inspection of Figure 2a; the mass pyrolysis flux at which the heat flux vs. mass flux correlation deviates from Branch I is inversely proportional to the degree of fuel dilution by nitrogen. At this point, the convective heat to the surface approaches a maximum value before it starts decaying until the flame reaches extinction. We will demonstrate that such a result is consistent with the proposition that the fuel concentration near the surface is constant (see Eq. 10d) when this deviation from 
Branch I occurs for the data shown in Fig. 2a. This deviation is due, of course, to finite chemical kinetics. Nevertheless, we are using again the thin flame diffusion analysis to gain some insight into the physics of combustion near a pyrolyzing surface. To demonstrate the validity of this statement, we have replotted the convective heat transfer data of Fig. $2 \mathrm{a}$ in Fig. $2 \mathrm{~b}$ by making the abscissa proportional to the fuel flow rate (supply flow rate times fuel concentration):

$\rho U S=\frac{\rho U}{r}=\rho U \frac{Y_{F T} V_{0} M_{0}}{Y_{o \infty} V_{F} M_{F}}=\rho U Y_{F T}$

Fig. $2 \mathrm{~b}$ shows that the net fuel flow rate at which heat flux is maximum is constant independent of the fuel dilution. By using the present analysis (see Eqs. 3 to 7) and the experimental results Corlett[9] (Figure 2b), we have deduced and proposed the following results:

1. The critical pyrolysis rate (at which the convective heat flux is maximum, Fig. 1) is given by:

$$
\left(\frac{\dot{m}_{p}{ }^{\prime \prime} c_{p}}{h_{c}}\right)_{c r i t} Y_{F T}=\text { constant depending on fuel gaseous kinetics }=\mathrm{C}_{\mathrm{e}}
$$

but otherwise independent of flow field through the Damkohler number. Here, we have used the fact that the convective heat flux coefficient $\mathrm{h}_{\mathrm{c}}$, equal to $\frac{k}{\delta}$ by definition, is constant for the test conditions shown in Fig. $2 b$.

2. By using Eqs. 3 and 4, we infer that at critical conditions

$$
\left(\mathrm{Y}_{\mathrm{FT}} \ln (1+\mathrm{B})\right)_{\text {crit }}=\text { constant }=\mathrm{C}_{\mathrm{e}}
$$

or

$$
Y_{F T} \ln \left(1+\frac{\chi_{A} Y_{\infty \infty} Q_{o}-\left(h_{w}-h_{\infty}\right)}{\dot{q}_{c}^{\prime \prime}} \dot{m}_{p}^{\prime \prime}\right)_{c r i t}=\text { const }=C_{e}
$$

In Eq. 10a we have modified the definition of convective mass transfer number (compare with Eq. 4) by introducing a combustion efficiency coefficient $\chi_{\mathrm{A}}$ (to account for incompleteness of combustion at extinction conditions) which will be determined experimentally. Condition (10a) can also be expressed in terms of fuel concentration at the surface by noting that the mass transfer number is also defined from:

$$
Y_{F S}=Y_{F T} \frac{B-r \chi_{A}}{B+1} \quad \text { or } \quad \frac{1}{1+\mathrm{B}}=1-\frac{\mathrm{r} \chi_{\mathrm{A}}+\mathrm{Y}_{\mathrm{FS}} / \mathrm{Y}_{\mathrm{FT}}}{1+\mathrm{r} \chi_{\mathrm{A}}}
$$

where: $Y_{\mathrm{FS}}$ is the fuel concentration on the surface, and $\mathrm{Y}_{\mathrm{FT}}$ is the fuel concentration in the supply stream. Thus, Eq. 10a becomes

$$
-\mathrm{Y}_{\mathrm{FT}} \ln \left(1-\frac{\mathrm{r} \chi_{\mathrm{A}}+\mathrm{Y}_{\mathrm{FS}} / \mathrm{Y}_{\mathrm{FT}}}{1+\mathrm{r} \chi_{\mathrm{A}}}\right)_{\text {crit }}=\mathrm{C}_{e}
$$

Eq. 10c can, near extinction, be approximated by: 


$$
Y_{F T} r \chi_{A}+Y_{F S}=\chi_{A} \frac{v_{f} M_{F}}{v_{o} M_{o}} Y_{o \infty}+Y_{F S}=C_{e}
$$

because $r \chi_{\mathrm{A}}$ is much less than one. It is interesting to emphasize that extinction criticality given by Eq. 9 is expressed in Eq. 10d as a sum of fuel concentration at surface and ambient oxygen concentration which is a relation between chemical species being independent of heat transfer coefficient, $h_{c}$, or the fuel dilution, $Y_{F T}$. We have used a series of experimental results to validate Eqs. 10a and 10c. These experimental results include: 1) surface heat flux measurements in a gaseous porous burner for fuels diluted by nitrogen [9]; 2) critical mass pyrolysis rates at reduced oxygen concentrations for various levels of external heat flux[10] or material preheating[11]; 3) critical mass pyrolysis rates at varying water drop application rates on the surface[12]; 4) critical mass pyrolysis rates of (transient) pyrolysis of a charring material exposed to various levels of external heat flux and/or oxygen concentrations, as performed as part of the present work. In this paper only items 1, 2, and 4 are included for discussion. For item 3, see Ref. 19.

\section{FUEL DILUTION BY AN INERT GAS}

It is seen from Fig. 2b that the mass flux of the fuel (not the total supplied mass flux) at critical conditions (i.e., maximum heat flux) is constant, independent of fuel dilution. The results in Fig. $2 b$ confirm the validity of our basic Eq. 9 because the heat transfer coefficient, $h_{c}$, is independent of fuel dilution in the present experiments as explained next. The convective heat transfer coefficient (see Eq. (9)) is expected to be constant for different dilutions because it is only slightly dependent on temperature $\left[\Delta \mathrm{T}^{1 / 3}\right.$ (turbulent), $\Delta \mathrm{T}^{1 / 4}$ (laminar)] [7], and the flame temperature does not vary much with dilution of the fuel because the mass stoichiometric air to fuel ratio is large. This estimate is verified as is shown in Fig. 2a. Using these data in Figure 2a for high supply rates, we have estimated a value of $h_{c}=10.0 \mathrm{~W} / \mathrm{m}^{2} \mathrm{~K}$ for the heat transfer coefficient in the present experiments $\left(\mathrm{Q}_{\mathrm{o}}=13,100 \mathrm{~kJ} / \mathrm{kg}, \mathrm{h}_{\mathrm{w}}=\mathrm{h}_{\infty}, \mathrm{c}_{\mathrm{p}}=1.0 \mathrm{~kJ} / \mathrm{kgK}, \mathrm{Y}_{\mathrm{o}_{\infty}}=.21\right)$. We have next used this heat transfer coefficient to determine the efficiency of combustion $\left(\chi_{\mathrm{A}}\right.$ in Eq. 10a) at the critical mass flux rate as shown in Table 1. The combustion efficiency is constant $\left(\chi_{\mathrm{A}}=.65\right)$, i.e., independent of dilution at critical extinction conditions.

TABLE 1. Combustion Efficiency at Critical Mass Flux Rates for Ethane-Nitrogen Gas Burners (Fig. 2a).

\begin{tabular}{cccc} 
Fuel Fraction & Total Flow & $\begin{array}{c}\dot{\mathrm{q}}_{\mathrm{c}} \\
(\text { measured }) \\
\left(\mathrm{kW} / \mathrm{m}^{2}\right)\end{array}$ & $\chi_{\mathrm{A}}$ \\
\hline $\mathrm{Y}_{\mathrm{FT}}$ & $\dot{\mathrm{m}}^{\prime \prime}\left(\mathrm{g} / \mathrm{m}^{2} \mathrm{~s}\right)$ & 17.6 & .68 \\
1. & 3.12 & 15.5 & .65 \\
.714 & 4.36 & 14.6 & .65 \\
.57 & 5.46 & 12.5 & .63
\end{tabular}




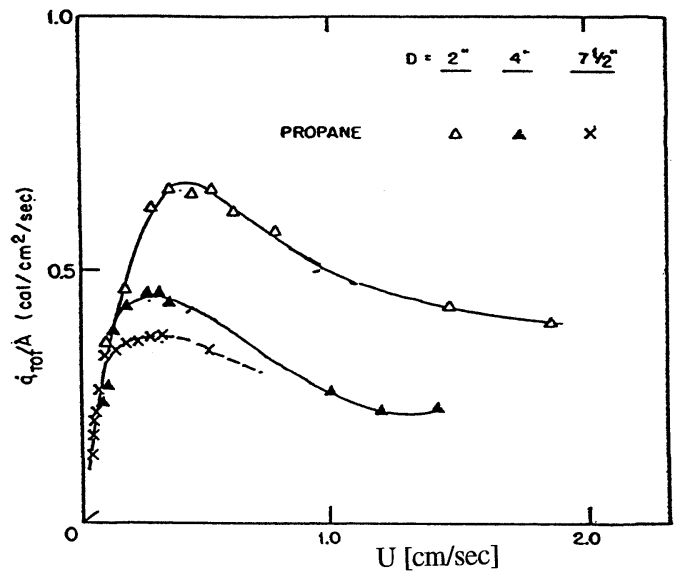

FIGURE 2c. Effects of diameter on critical fuel mass flux and total heat transfer flux to the burner for propane; $U$ is the average fuel gas velocity at the burner (from Ref. 9).
We have also reproduced in Figure $2 \mathrm{c}$ another figure from Corlett's report[9], which further supports the validity of Eq. 9. This figure shows the effect of "pool" diameter on the critical mass flux, namely, as the diameter, D, increases, the critical mass flux (i.e., mass flux at the maximum convective or total heat flux) decreases.

By using Eq. 9, one can explain this behavior by observing that the convective heat transfer coefficient, $h_{c}$, increases as $D^{-}$ ${ }^{1 / 4}$ for laminar conditions while it is independent of diameter for turbulent conditions. This agreement is supported by further experiments presented in following sections, as well as by comparison with stagnation flow diffusion flame experiments on porous cylinders and their numerical solutions[13,14,15], as discussed in the final section of this paper.

\section{OXIDANT STREAM DILUTION BY NITROGEN}

We consider two sets of experiments, both for PMMA (polymethylmethacrylate) conducted at varying external heat fluxes[10] and at various material initial preheating temperatures[11] of PMMA. Fig. 3a shows mass pyrolysis rate measurements and critical conditions for extinction taken from Ref. [10] in which $10 \mathrm{~cm}$ diameter samples of PMMA were exposed to various levels of external heat flux and various levels of oxygen dilution by nitrogen. For the data in Fig. 3a corresponding to molal oxygen concentrations of $.18, .19, .21$ critical extinction conditions (namely, the level of negative external heat flux e.g. by cooling) have been determined by the intercept of the corresponding straight lines for pyrolysis rates with the straight horizontal line $\mathrm{m}$ " $=5 \mathrm{~g} / \mathrm{m}^{2} \mathrm{~s}=$ mass pyrolysis rate at extinction, which is the mass pyrolysis at extinction independent of oxidant dilution.

In Figure $3 b$ we plot all the data corresponding to extinction conditions for PMMA taken from References [10] and [11]. For each extinction condition, a point in Fig. 3b is defined having coordinates the mass pyrolysis at extinction (abscissa), and the total heat flux to the surface (ordinate). The total heat flux is calculated by applying an energy balance on the surface for cases reported in [10] and [11] as shown in Table 2 for the results in Fig. 3a. It is also evident from Fig. $3 \mathrm{~b}$ that the critical mass pyrolysis rate for the smaller scale (1 $\mathrm{cm}$ diameter) PMMA experiments[11], although constant, is $19.2 \mathrm{~g} / \mathrm{m}^{2} \mathrm{~s}$, namely, much higher than the constant value in Tewarson's[10] experiments, i.e., $5 \mathrm{~g} / \mathrm{m}^{2} \mathrm{~s}(10 \mathrm{~cm}$ diameter). These results shown in Fig. $3 \mathrm{~b}$ are consistent with Eq. 9 because: a) critical pyrolysis rates are constant for each set of experiments, i.e., independent of oxidant dilution; and b) but, the critical mass pyrolysis value depends on the convective heat transfer coefficient, $h_{c}$, in Eq. 9), which increases as the sample size decreases; indeed, estimates of convective heat fluxes (not included here[16,19]) based on Eqs. 9 and 10a further strengthen the validity of the present model. 


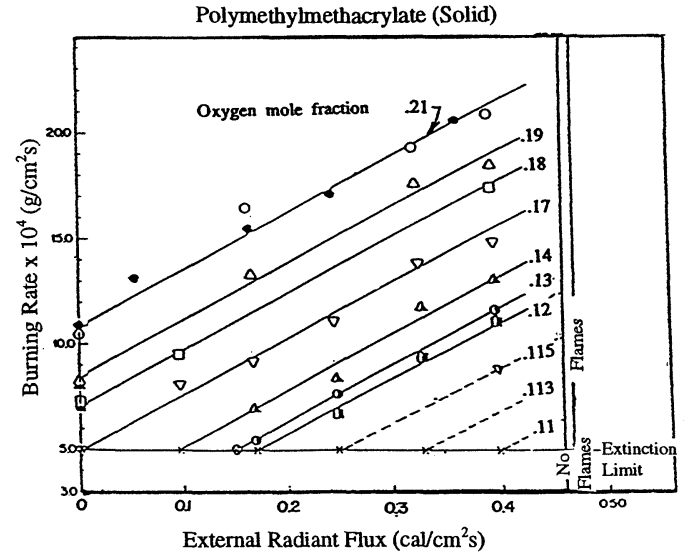

FIGURE 3a. Mass pyrolysis rate of PMMA as a function of external heat flux at constant values of various oxygen mole fractions, $.21, .19, .18, .17, .14, .13, .12, .115$ (from Tewarson ${ }^{10}$.

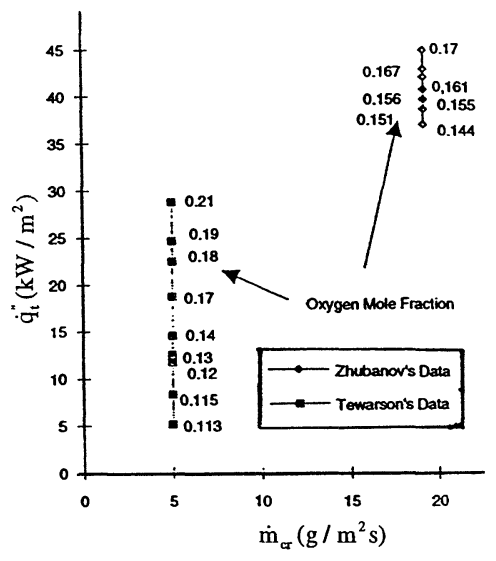

FIGURE 3b. Total heat flux at critical pyrolysis rate deduced for PMMA results reported in Refs. 10 and 11.

TABLE 2. Heat Fluxes for PMMA at Extinction (Fig. 3a).

\begin{tabular}{cccc}
$\begin{array}{c}\text { Mole Fraction } \\
\text { of Oxygen }\end{array}$ & $\begin{array}{c}\text { Mass Fraction } \\
\text { of Oxygen }\end{array}$ & $\begin{array}{c}\text { Total Heat* } \\
\text { Flux }\left(\mathrm{kW} / \mathrm{m}^{2}\right)\end{array}$ & $\begin{array}{c}\text { Convective** } \\
\text { Heat Flux }\left(\mathrm{kW} / \mathrm{m}^{2}\right)\end{array}$ \\
\hline .21 & .23 & 29.8 & 18.2 \\
.19 & .21 & 24.3 & 16.31 \\
.18 & .20 & 22.4 & 15.3 \\
.17 & .19 & 18.7 & 14.4 \\
.14 & .16 & 14.6 & 11.51 \\
.13 & .146 & 11.6 & 10.2 \\
.115 & .13 & 8.29 & $8.6 * * *$ \\
.113 & .127 & 5.15 & 8.34 \\
.11 & .124 & 2.02 & 8.06
\end{tabular}

$* \dot{\mathrm{q}}_{\mathrm{f}}^{\prime \prime}=\dot{\mathrm{m}}^{\prime \prime} \Delta \mathrm{H}_{\mathrm{v}}+\dot{\mathrm{q}}_{\mathrm{rr}}^{\prime \prime}-\dot{\mathrm{q}}_{\mathrm{e}}^{\prime \prime}$, where $\dot{\mathrm{q}}_{\mathrm{e}}^{\prime \prime}$, (from Fig. 3a), $\Delta \mathrm{H}_{\mathrm{v}}=1848 \mathrm{k} \mathrm{J} / \mathrm{kg}, \dot{\mathrm{q}}_{\mathrm{rr}}^{\prime \prime}=\sigma \mathrm{T}_{\mathrm{p}}^{4}=9.5 \mathrm{~kW} / \mathrm{m}^{2}, \dot{\mathrm{m}}^{\prime \prime}=5 \mathrm{~g} / \mathrm{m}^{2} \mathrm{~s}$. **Use Eqs. (9), (10a) with assumed $\chi_{\mathrm{A}}=.65$ (see Table 1), $\mathrm{Q}_{0}=13,100 \mathrm{~kJ} / \mathrm{kg}, \dot{\mathrm{m}}^{\prime \prime}=5 \mathrm{~g} / \mathrm{m}^{2} \mathrm{~s}, \mathrm{~h}_{\mathrm{c}}=13.61 \mathrm{~W} / \mathrm{m}^{2} \mathrm{~K}$. ***The last three points represent extinction by quenching of the gaseous phase (slow gaseous reactions) and not by interaction of flames with the pyrolyzing surface (see also text). 

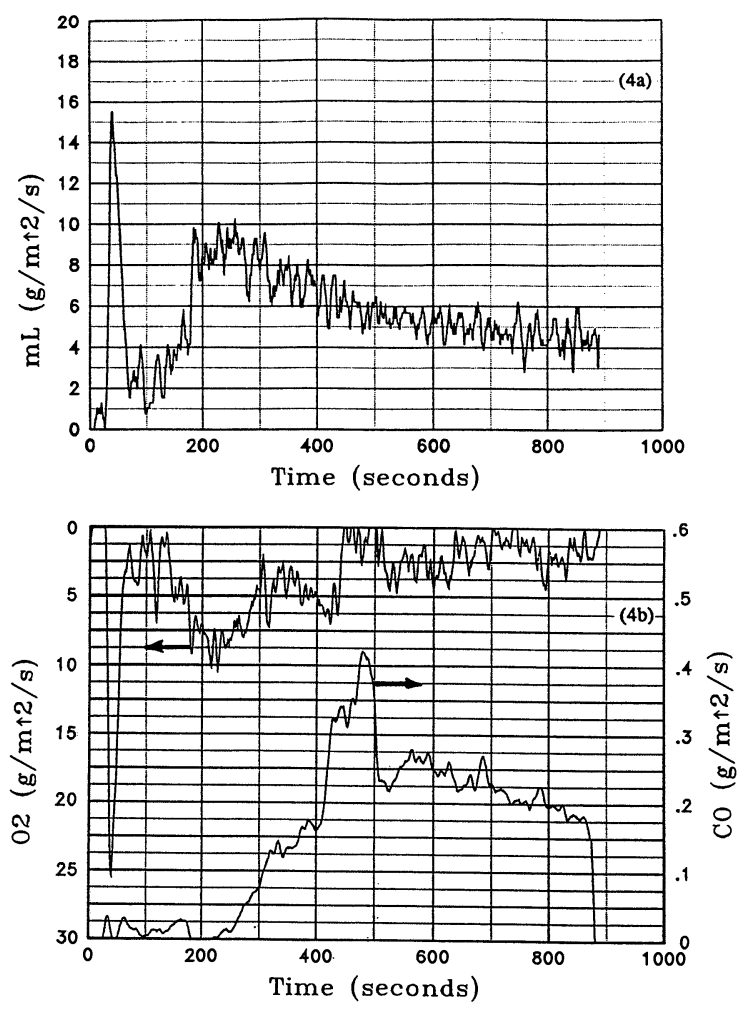

FIGURE 4. Mass loss rate for particle board until flame extinction occurs at $400 \mathrm{~s}$ for the following conditions: external heat flux 35 $\mathrm{kW} / \mathrm{m}^{2}$, at ambient air (4a). Flame extinction is observed visually and supported by measurements of oxygen depletion and carbon monoxide (4b).
To further validate the present approach for measuring critical mass pyrolysis rates, we have performed extinction experiments in a flammability apparatus available at FMRC[17]. Particle board samples (diameter $9.65 \mathrm{~cm}$, thickness, $1.9 \mathrm{~cm}$ ) can be exposed to various levels of external heat flux and at various levels of oxygen concentration of ambient air. Mass loss histories, species concentrations, oxygen depletion and heat release rates are obtained using a load cell and gas analysis of the products of combustion collected by a hood[17]. To speed up the initial ignition process, we have spread a few milliliters of acetone on top of the particle board for running the present experiments. Figures $4 \mathrm{a}$ and $4 \mathrm{~b}$ show measurements of mass loss (pyrolysis) rate, oxygen depletion and carbon monoxide in which a particle board sample was exposed to $35 \mathrm{~kW} / \mathrm{m}^{2}$ external heat flux at ambient conditions (other heat fluxes and vitiated ambient conditions were also investigated). Following the initial spike in mass loss rate (Fig. 4a) which corresponds to acetone consumption, particle board starts pyrolyzing and burning.

Subsequently, the mass loss rate increases to a maximum value and then starts decreasing owing to char formation. During this period, flaming combustion occurs until the heat release rate and the pyrolysis rate decreases below a critical value. Flaming was observed to stop both visually and also by the increase in $\mathrm{CO}$ production, as illustrated in Fig. $4 \mathrm{~b}$.

For all these tests, the critical mass pyrolysis rate at extinction (when no flaming is sustained) is 5.5 $\mathrm{g} / \mathrm{m}^{2} \mathrm{~s}$ with an accuracy $\pm 4 \%$. 
The present work validates (see Figs. 2,3,4) the new critical extinction conditions presented by Eqs. 9, 10a as shown in see Fig. 1. A novel formulation of critical conditions is given by Eq. 10d, based on a sum of chemical species mass fraction of fuel near the surface and ambient oxygen being constant. The present approach is physically explained and more general than previous empirical approaches[7,8]. These conditions for extinction can be measured in a flammability apparatus. The critical pyrolysis rate relation at extinction is applicable for various extinction agent applications including fuel dilution by inert agents, oxidant dilution by inert agents, or water application on the surface. The model does not only provide the critical mass pyrolysis rate, but also the convective heat flux to the surface (see Eqs. 10a and Tables 1,2). We have also found that the mass transfer number should be modified by an efficiency coefficient (see Eq. 10a, applicable near extinction conditions), which has been estimated to be constant i.e., independent of Damkohler number, for a given fuel $\left(\chi_{\mathrm{A}}=.65\right.$ for ethane gaseous burner, Table 1$)$, independent of dilution (or flow strain).

The present results are also consistent with Tsuji 13$]$ experiments and numerical simulations, Tien[14], Sibulkin[6], although more work, including detailed chemistry (rather than global reaction rates) is needed to verify and delineate the limitations of the present model. We include Figure 5 taken from Olsen and Tien's[14] paper to substantiate our claim here.

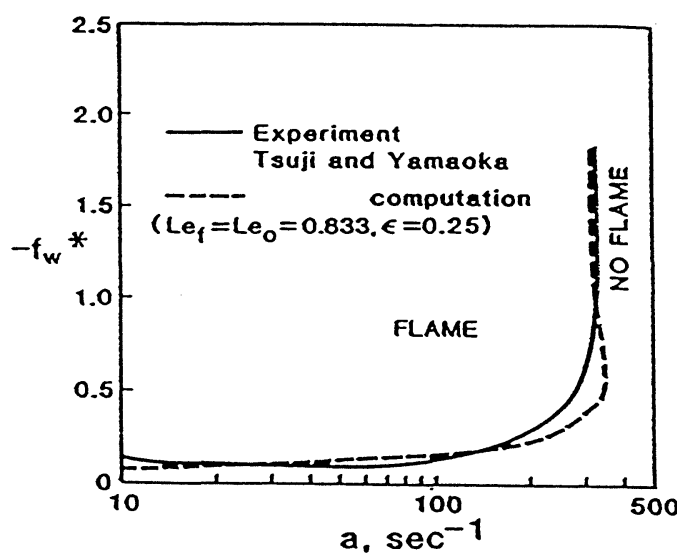

FIGURE 5. Computed and experimental mass flux at extinction conditions normalized by the heat transfer coefficient in terms of straining rate, $\boldsymbol{\alpha}$, in counterflow diffusion flame on a cylinder. At low straining rates, extinction mass flux is nearly constant (independent of straining rate) in accordance with present results (Eq. 9).
This figure includes the extinction curve for a stagnation flow (experiments by Tsuji[13]), on a porous cylinder supplying a flammable gas. The ordinate is the dimensionless mass supply rate (essentially proportional to $\frac{\dot{m}_{p}{ }^{\prime \prime} c_{p}}{h_{c}}$ in our definition of critical condition). The abscissa is the nominal strain rate. Extinction occurs when the mass supply rate becomes less than the value shown in Figure 5. Our extinction conditions correspond to the low straining rates in Figure 5, wherein extinction occurs by interaction of flame with the surface. In this regime, both experiments (notwithstanding buoyancy effects at very low straining rates) and numerical computations show that the dimensionless supply rate at extinction (which is proportional to our parameter $\frac{\dot{m}_{p}{ }^{\prime \prime} c_{p}}{h_{c}}$ ) is constant and independent of straining rate, in consistency with our model. It should be noted that extinction conditions in Figure 5 do not exactly correspond to extinction conditions in a condensed fuel (where maximum convective heat flux occurs). 
This work was supported by a grant from NIST/BFRL and by FMRC. We thank the contract monitor W. Grosshandler of NIST/ BFRL for many discussions and P.A. Croce of FMRC for encouragement and comments.

\section{REFERENCES}

1. Frank-Kamenetskii, D.A. "Calculation of Thermal Explosion Limits," Acta Phys.-chim, URSS 10, 365, 193.

2. Friedlander, S.K. and Keller, K.H., "The Structure of the Zone of Diffusion-Controlled Reaction," Chem. Engrg., Sci. 18, 365, 1939.

3. Fendell, P.E., "Ignition and Extinction in Combustion of Initially Unmixed Reactants," J. Fluid Mech., 21, 282-303 (1965).

4. Linan, A. and Williams, F.A., "Theory of Ignition of a Reactive Solid by Constant Energy Flux," Comb. Sci. Tech, 3, 91.

5. Law, C.K., "Asymptotic Theory of Ignition and Extinction in Droplet Burning," Combustion and Flame, 24: 89-98, 1975.

6. $\quad$ Sibulkin, M., "Free Convection Diffusion Flames from Burning Solid Fires," Prog. Energy Combust. Sci. 14: 195-212, 1988.

7. Beyler, C., "A Unified Model of Fire Suppression," J. of Fire Prot. Engr. 4 (1), pp. 5-16, 1992.

8. Rasbash, D.J., "Theory in the Evaluation of Fire Properties of Combustible Materials," Proceedings of the Fifth International Fire Protection Seminar, Karlsruhe, Germany, 1976, pp. 113-130.

9. Corlett, R.C. "Heat Transfer Data Summary - Pool Burning Study," Division of Eng. Applied Sciences, Eng. Science Laboratory, Harvard University, Technical Report 19, 1965.

10. Tewarson, A. and Pion, R.R., "Flammability of Plastics - I. Burning Intensity," Combustion and Flame, 26, 85-103, 1976.

11. Zhubanov, T.B. and Gibov, K.M., "Oxygen Index and Minimum Tasks of Polymer Combustion," Fire and Materials, 12, 169-172, 1988.

12. Magee, R.S., and Reitz, R.D., "Extinguishment of Radiation Augmented Fires by Water Sprays," Fifteenth Symposium International on Combustion, The Combustion Institute, Pittsburgh, PA, 1975.

13. Tsuji, H., "Counterflow Diffusion Flames," Prog. Energy Combust. Sci., 8, 93-119, 1982.

14. Olson, S.L. and Tien, J.S., Combust. and Flame, 70, 161-170, 1987.

15. Oh, T.K., Lee, J.S., and Chung, S.H., Int. J. Heat Mass Transfer, 37, 2983-2900, 1994.

16. Mudan, K.J. and Croce, P.A., Chapt. 3-11 in SFPE Handbook of Fire Protection Engineering, 2nd Edition, NFPA, 1995.

17. Tewarson, A., "Generation of Heat and Fire Products," FMRC Report J.I. OR0J4.RC(3), 1995.

18. Vlachos, D.G., Schmidt, L.D., Aris, R., "Ignition and Extinction of Flames Near Surfaces: Combustion of $\mathrm{CH}_{4}$ in Air," AIChE, Journal, 40: 1005-10017, 1994.

19. Dlichatsios M.A., "Required Water Density for Fire Extinguishment and Control," Annual Report for NIST grant \# 60NANB4D167, 1996. 